\title{
Anti-tumor effects of lidocaine on human gastric cancer cells in vitro
}

\author{
Ye $\mathrm{L}^{1}$, Zhang $\mathrm{Y}^{1}$, Chen $\mathrm{YJ}^{1}$, Liu $\mathrm{Q}^{2}$ \\ Department of Integrated Traditional Chinese and Western Medicine, The Second Affiliated Hospital of Fujian \\ Medical University combined with the Oncology, Quanzhou, China. liuqiang14789@163.com
}

\begin{abstract}
Currently, there exists an urgent need to investigate the anti-cancer effects of lidocaine on gastric cancer cells. The purpose of the present study was to evaluate the anti-tumor effects and the underlying mechanisms of lidocaine in gastric cancer cells. Our results indicated that lidocaine significantly suppressed proliferation, migration and invasion and induced apoptosis in a dose-dependently manner in human gastric cancer cells. In addition, our data shown that the expression of $\mathrm{Bcl}-2$ was decreased and the level of Bax was increased by lidocaine treatment. Furthermore, we found that lidocaine altered the protein expression of the MAPK pathway. p-p38 was also increased simultaneously, while the level of p38 was not changed. In summary, lidocaine has a prominent anti-tumor activity on gastric cancer cells and is a promising therapeutic agent for the treatment of gastric cancer (Fig. 4, Ref. 32). Text in PDF www.elis.sk.

KEY WORDS: lidocaine, gastric cancer cells, anti-tumor effect, MAPK pathway.
\end{abstract}

\section{Introduction}

Gastric cancer (GC), one of the most frequent type of malignant diseases, has a poor 5-year survival rate (1-2). Also, gastric cancer (GC) has high rates of recurrence and metastasis in digestive system (3-4). In China, GC accounted for $40 \%$ of the world diseases annually that were ranked the second morbidity and the third mortality of the malignant tumors around the world (5). Excitedly, the incidence of gastric cancer has reduced worldwide over the last 3 decades. Moreover, we have made achievements in the diagnosis and treatment of gastric cancer. Currently, due to the loss of specific and effective therapies, most patients have accessed to the tail stage with poor treatment and poor prognosis (6). Surgery, chemotherapy and radiation therapy have been recommended for GC patients (7). However, the rapid development of new chemotherapeutic agents had not improved the prognosis of gastric cancer, the prognosis of gastric cancer patients remains poor (8-9) with the overall 5-year survival rates ranging from 5 to $15 \%(10)$. Besides, the effect of nursing practices on clinical treatment of gastric cancer has also received an increasing atten-

\footnotetext{
${ }^{1}$ Department of Integrated Traditional Chinese and Western Medicine, The Second Affiliated Hospital of Fujian Medical University combined with the Oncology, Quanzhou, China, and ${ }^{2}$ General Surgery, the Third Affiliated Hospital of Shandong Academy of Medical Sciences, Shandong Institute of Parasitic Diseases, Jining, China

Address for correspondence: Q. Liu, The Third Affiliated Hospital of Shandong Institute of Parasitic Diseases, No. 11 Taibai Lou Middle Road, Jining 272033, China.

Phone: 0537.2350967, Fax: 0537.2353277
}

tion. A lot of evidence suggested that incorporating holistic nursing of psychological and physical components into routine ward nursing could effectively improve the quality of life and enhance the survival time for patients $(11,12)$. The molecular mechanisms underlying growth and metastasis of gastric cancer remain unknown. Therefore, there is an urgent need to identify the molecular mechanisms underlying the development and progression of gastric cancer and characterize new pharmaceutical treatment targets within gastric cancer cells $(13,14)$.

Recent years, lidocaine is mainly used as a local anesthetics, and has many other effects. Numerous reports showed that lidocaine could improve the neurological outcome of cats in experimental studies (15) and reduce the incidence of lumbar in rats (16). In addition, according to reports, lidocaine has many functions, including depressing the inflammatory reaction $(17,18)$, protecting against an acute lung injury (19-21) and reducing postoperative cognitive dysfunction (POCD) (22-24). There is also the study, which indicated that lidocaine might have anti-cancer actions in a wide range of cancer cells (25-29), and it may have sensitizing effects on anti-cancer drugs $(30,31)$. Up to date, no reports have investigated whether lidocaine can affect the viability, invasion and migration of gastric cancer cells, and its potential anti-cancer effects on gastric cancer cells were not fully understood. Here, in the present study, we investigated the role of lidocaine in gastric cancer cells in vitro. Lidocaine significantly inhibited the proliferation, invasion, migration and increased apoptosis in SGC7901 and BGC823 cells in a concentration-dependent manner. In addition, lidocaine significantly increased the expression levels of Bax, p-ERK1/2, p-p38 and decreased the levels of Bcl-2 in gastric cancer cells. However, the levels of ERK1/2and p38 were not significantly changed. 


\section{Materials and methods}

\section{Cell culture and treatment}

Human gastric cancer cell lines (SGC7901, BGC823) were purchased from the Type Culture Collection of the Chinese Academy of Sciences (Shanghai, China). All the cells were cultured in RPMI-1640 medium (Gibco, Gaithersburg, MD, USA); supplemented with $10 \%$ FBS (Gibco, USA), $100 \mathrm{mg} / \mathrm{ml}$ streptomycin, and $100 \mathrm{u} / \mathrm{ml}$ penicillin (HyClone, USA). The cells grown at $37^{\circ} \mathrm{C}$ in a humidified incubator containing $5 \% \mathrm{CO}_{2}$. Cells were treated with various concentrations of lidocaine $(0,0.1,0.5,1,5$, and $10 \mathrm{mM}$ ) for $24 \mathrm{~h}, 48 \mathrm{~h}, 72 \mathrm{~h}$ at $37^{\circ} \mathrm{C}$ as described previously.

\section{Cell viability analysis}

Cell proliferation was determined using an MTT assay. Cells were cultured in 96 -well plates (104 cells/plate) at $37^{\circ} \mathrm{C}$ for 24 $\mathrm{h}$, then exposed to various concentrations of lidocaine $(0,0.1,0.5$, 1,5 , and $10 \mathrm{mM}$ ) at $37^{\circ} \mathrm{C}$ for $24 \mathrm{~h}, 48 \mathrm{~h}, 72 \mathrm{~h}$. Then the culture medium was removed, and MTT solution was added $(10 \mu \mathrm{l})$ to the medium and following incubation for another $4 \mathrm{~h}$ at $37{ }^{\circ} \mathrm{C}$. The supernatants were removed and DMSO (100 $\mu 1$, KeyGen Biotech) was added to dissolve the formazan crystals. The optical density (OD) was measured at $490 \mathrm{~nm}$ using a microplate reader.

\section{Apoptosis assay}

Flow cytometry (BD Accuri ${ }^{\mathrm{TM}}$ Flow Cytometer, USA) was performed to analyze cell apoptosis. Human gastric cancer cells were treated with DMSO or different concentrations of lidocaine $(0,1,5 \mathrm{mM})$ for $48 \mathrm{~h}$. Then, the cells were stained with Annexin V-FITC and PI (KeyGen Biotech, China) following the manufacturer's protocol. The cells in early stages of apoptosis were Annexin V positive and PI negative, and the cells in the late stages of apoptosis were both Annexin V and PI positive. The data were analyzed using Flow Jo 7.6 software (TreeStar Inc, USA).

\section{Transwell assay}

Transwell inserts (24-well) with an 8- $\mu$ m pore size (Corning Incorporated, Corning, NY, USA) were used in the migration and invasion assays. Matrigel pre-coated membranes were precoated with $100 \mu \mathrm{l}$ medium in invasion assay. Gastric cancer cells were seeded in the upper chamber, while the lower chamber contained $600 \mu 11640$ with different concentrations of lidocaine $(0,1,5 \mathrm{mM})$ were incubated at $37{ }^{\circ} \mathrm{C}$ for $48 \mathrm{~h}$. After incubation, cotton swabs were used to discard the cells, which had not invaded through the membrane pores. The membrane inserts were then fixed with $4 \%$ paraformaldehyde and stained with $1 \%$ gentian violet solution. In addition, we counted the number of migrating and invading cells under a microscope.

\section{Western blot analysis}

SGC7901 and BGC823 cells were treated with lidocaine $(0$, $1,5 \mathrm{mM}$ ) for $48 \mathrm{~h}$. Total cellular protein extracted with RIPA buffer containing $0.1 \%$ PMSF. BCA protein assay kit (Pierce, USA) was used to evaluate the protein concentrations. Then the samples were heated at $100{ }^{\circ} \mathrm{C}$ for $5 \mathrm{~min}$ to denature the proteins, separated by $10 \%$ SDS/PAGE and transferred to a PVDF membrane (Millipore, USA). Following this, the membranes were blocked with $5 \%$ non-fat milk for $1 \mathrm{~h}$ at room temperature and incubated with primary antibodies including p-38, p-p38, Bcl-2, Bax and $\beta$-actin overnight at $4{ }^{\circ} \mathrm{C}$. Subsequently, the membranes were incubated with the anti-rabbit IgG antibody at room temperature for $2 \mathrm{~h}$. At last, we used EasySee Western Blot Kit (Beijing TransGen Biotech, Beijing, China) to detect the chemiluminescence signals. ImageJ 1.43 software was used to analysis the densitometric.
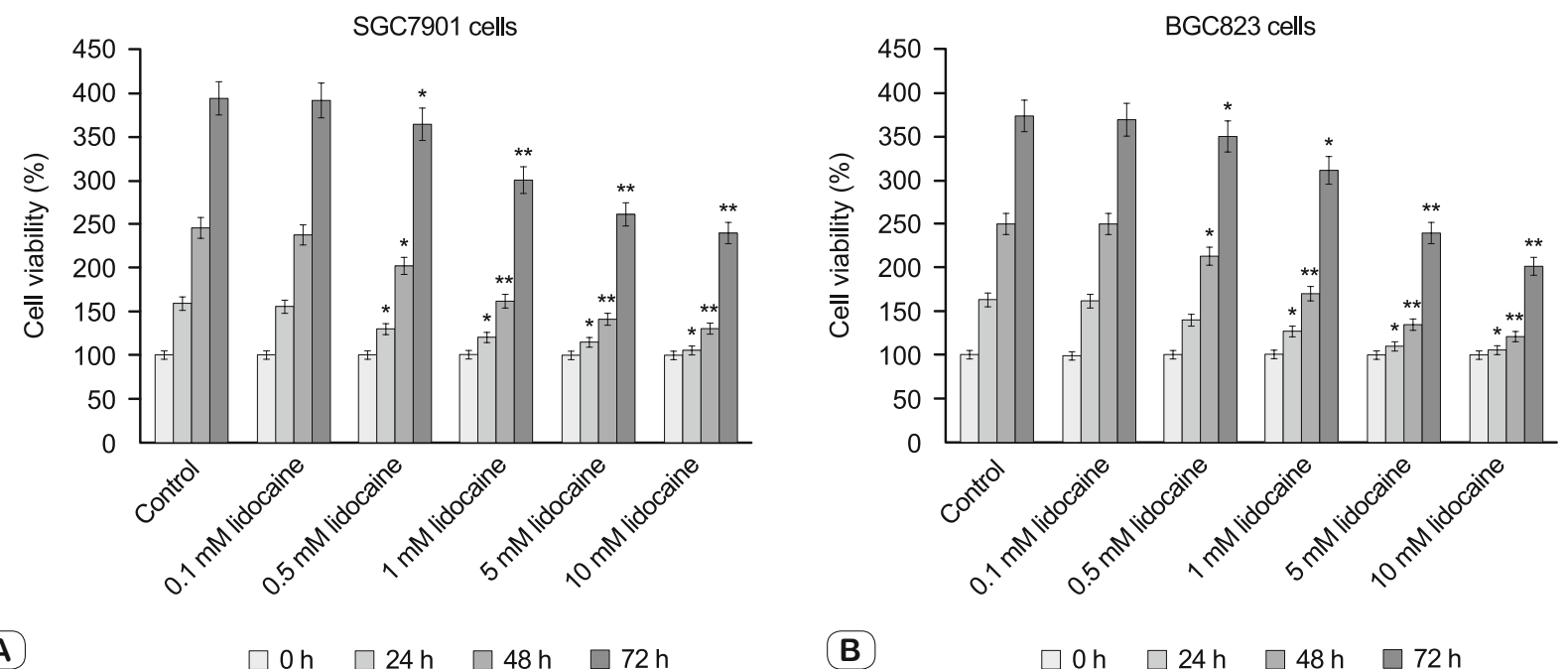

Fig. 1. Lidocaine inhibited the proliferation of gastric cancer cells. (A) SGC7901 cells were treated with various concentrations of lidocaine (0, $0.1,0.5,1,5$, and $10 \mathrm{mM}$ ) for $24,48,72 \mathrm{~h}$, and cell viability was detected by MTT assay. (B) BGC823 cells were treated with various concentrations of lidocaine $(0,0.1,0.5,1,5$, and $10 \mathrm{mM})$ for $24,48,72 \mathrm{~h}$, and cell viability was detected by MTT assay. All values represented as mean $\pm \mathrm{SD}, \mathbf{n}=3,{ }^{*},{ }^{* *} \mathbf{p}<\mathbf{0 . 0 5}, 0.01$ vs Control. 
A
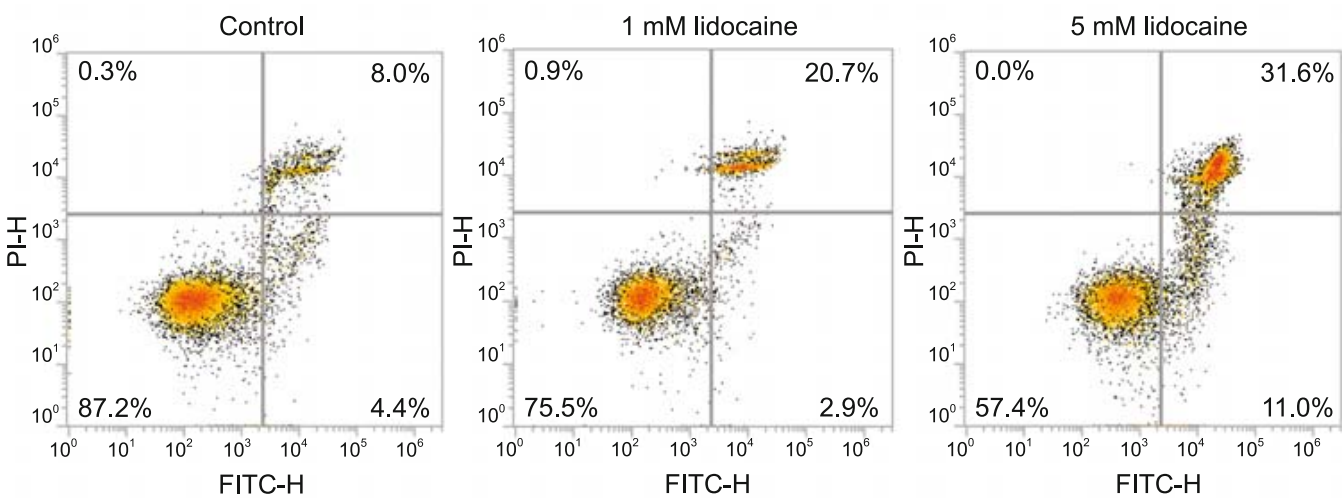

B
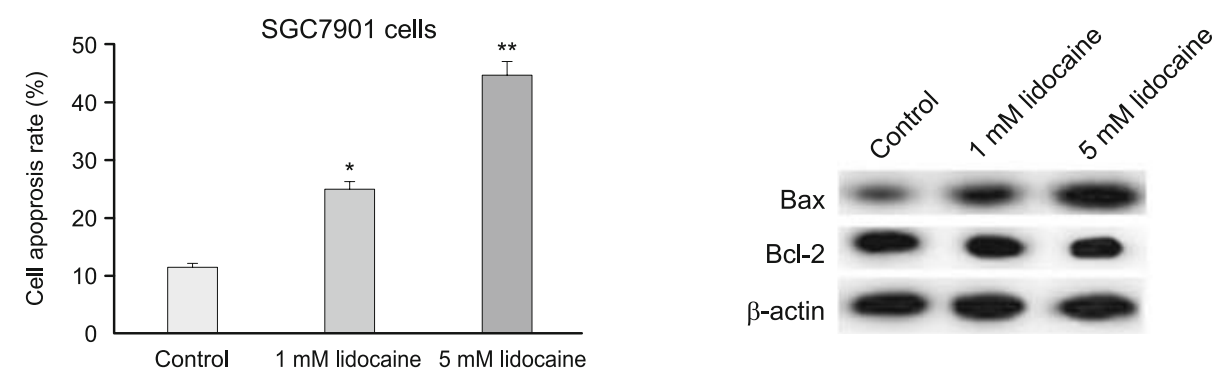

(C)
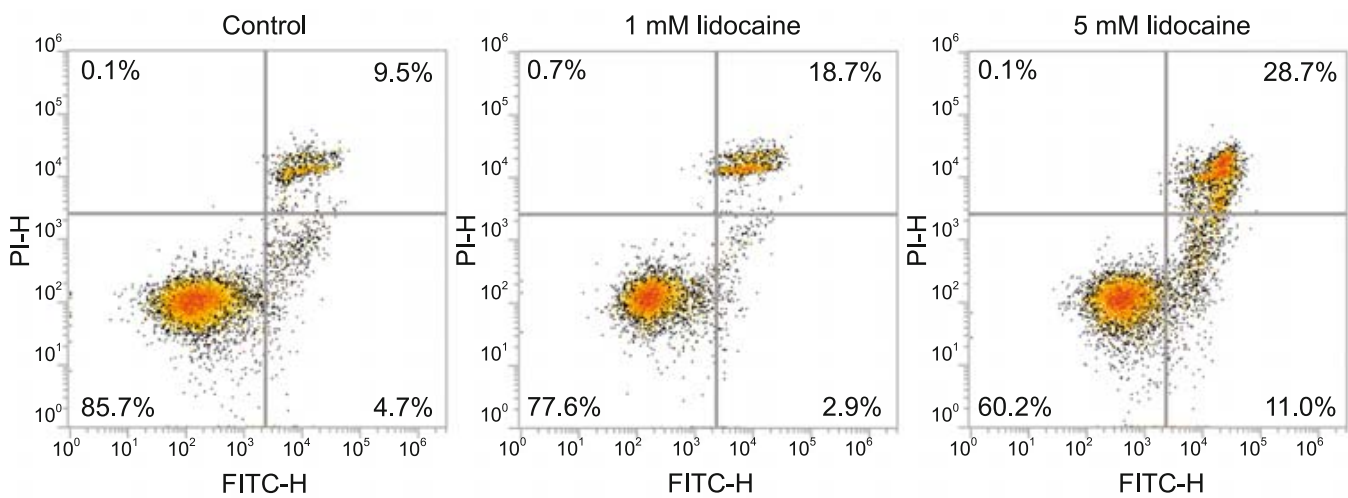

(D)
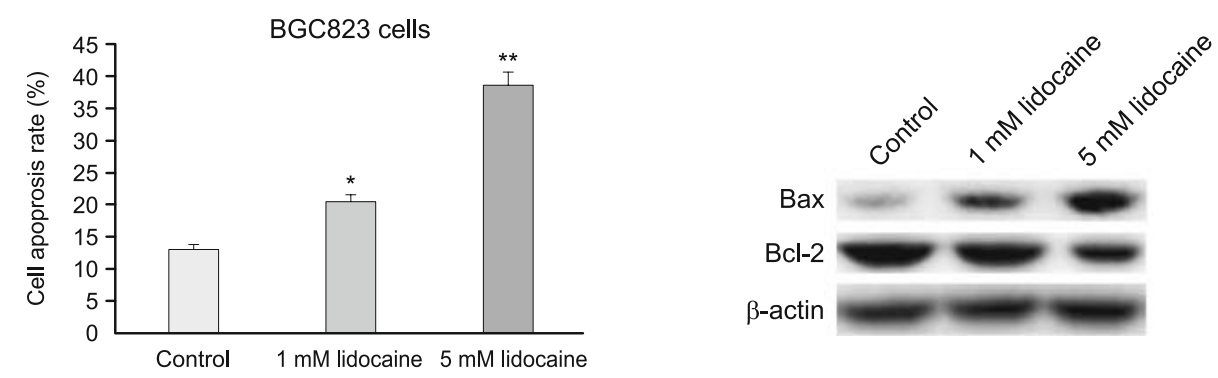

Fig. 2. Lidocaine induced apoptosis in gastric cancer cells. (A) After treatment with various concentrations of lidocaine for 48 h, SGC7901 cells were stained with annexin V-FITC and PI for analysis using flow cytometry. Percentages of apoptotic cells were quantified and presented in the histogram. (B) Western blot analysis of Bax and Bcl-2 protein in SGC7901 cells treated with lidocaine (0, 1, $5 \mathrm{mM})$ for $48 \mathrm{~h}$. (C) After treatment with various concentrations of lidocaine for $48 \mathrm{~h}$, BGC823 cells were stained with annexin V-FITC and PI for analysis using flow cytometry. Percentages of apoptotic cells were quantified and presented in the histogram. (D) Western blot analysis of Bax and Bcl-2 protein in BGC823 cells treated with lidocaine $(0,1,5 \mathrm{mM})$ for $48 \mathrm{~h}$. Data are shown as the mean $\pm \mathrm{SD} . *, * * \mathrm{p}<0.05,0.01$ compared to the control group. The experiments were performed in triplicate. 
Statistical analysis

The results were expressed as the mean $\pm \mathrm{SD}$. Statistical analysis including Student's t-test, ANOVA analysis and Correlation analysis, performed with GraphPad software. $\mathrm{p}<0.05$ was considered as statistically significant.

\section{Results}

Lidocaine inhibited the proliferation of gastric cancer cells

Lidocaine inhibited gastric cancer cells viability in an approximately dose-dependent and time-dependent manner at different concentrations $(0,0.1,0.5,1,5$, and $10 \mathrm{mM})$ for 24,48 and $72 \mathrm{~h}$ compared to the control cells as detected by the MTT Assay. Notably, treatment with $0.5,1,5$, and $10 \mathrm{mM}$ lidocaine for 24,48 and 72 hours resulted in significant reductions in cell viability (Fig. 1). In this study, time of $48 \mathrm{~h}$ was selected to be used in the following experiments.

Lidocaine induced apoptosis of gastric cancer cells

Then we detected whether lidocaine could trigger apoptosis in gastric cancer cells. Annexin V-fluorescein isothiocyanate (FITC)/propidium iodide (PI) was used to measure the effects of SGC7901 and BGC823 cells after various concentrations of lidocaine treatment for $48 \mathrm{~h}$. We observed that lidocaine treatment induced cell apoptosis in dose-dependent manner (Fig. 2A). Our findings indicated that lidocaine inhibited cell proliferation partly due to the induction of cell apoptosis by lidocaine in the gastric cancer cells. The protein expression levels were detected by western blot assay. We found that the protein expression of Bax was significantly increased by lidocaine in a dose-dependent manner. In addition, Bcl-2, which plays an important role in cell apoptosis, was inactivated upon lidocaine treatment (Fig. 2B).

\section{Lidocaine retarded cell migration and invasion}

To analyze whether lidocaine could retard the cell migration and invasion in gastric cancer cells, the effects of lidocaine on migration and invasion of SGC7901 and BGC823 cells were examined by the transwell assay. The results indicated that the migration and invasion capability of SGC7901 and BGC823 cells decreased gradually with increased concentrations of lidocaine compared to that of the control (Figs 3A and 3B). Taken together, lidocaine has anti-migratory and anti-invasive function in gastric cancer cells.

\section{Lidocaine activated the p38MAPK signaling pathway}

In order to identify the potential molecular mechanisms by which lidocaine affects gastric cancer cells, the MAPK signaling pathway was analyzed. Then we examined the related proteins including p-p38 and p38. The results demonstrated that in
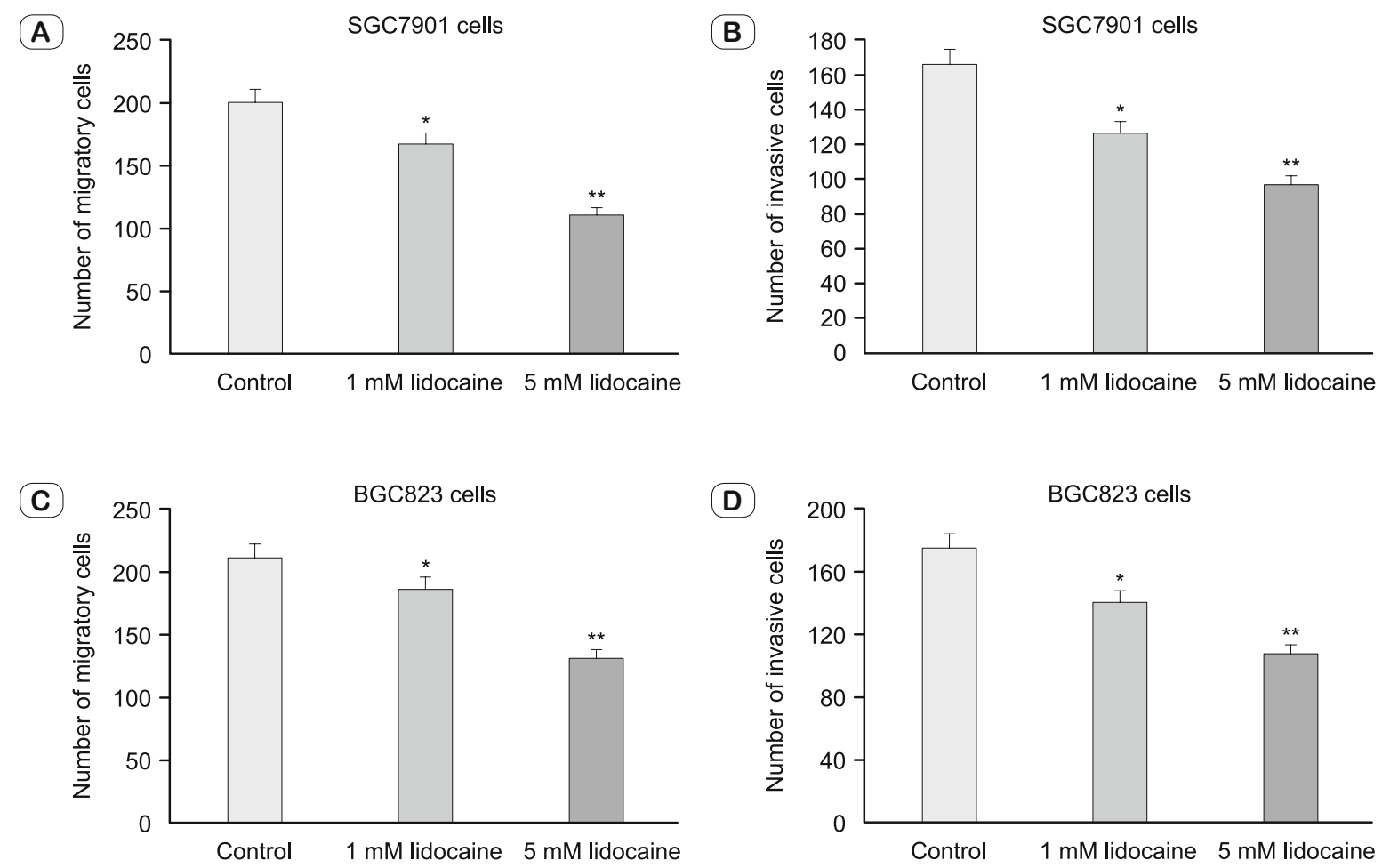

Fig. 3. Lidocaine inhibited migration and invasion of gastric cancer cells. (A and B) SGC7901 cells were treated with lidocaine at various concentrations of $0,1,5 \mathrm{mM}$ for $48 \mathrm{~h}$. Then transwell assays were performed to study cell migration and invasion, and the number of migratory and invasive cells were calculated and presented. (C and D) BGC823 cells were treated with lidocaine at various concentrations of $0,1,5 \mathrm{mM}$ for $48 \mathrm{~h}$. Then transwell assays were performed to study cell migration and invasion, and the number of migratory and invasive cells were calculated and presented. Data are shown as the mean \pm SD. ${ }^{* *} \mathbf{p}<0.05,0.01$ compared to the control group. 
(A)

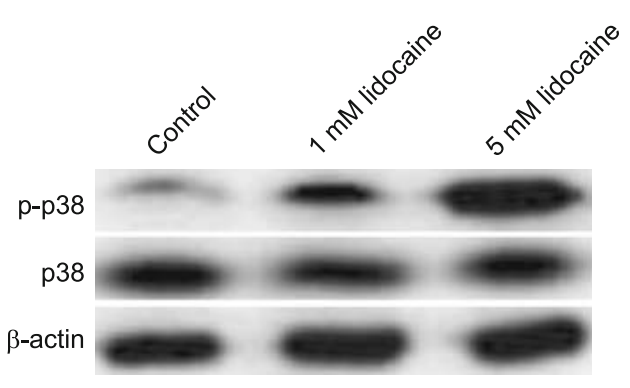

B

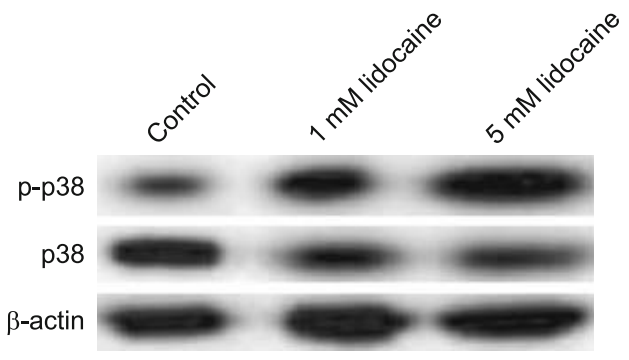

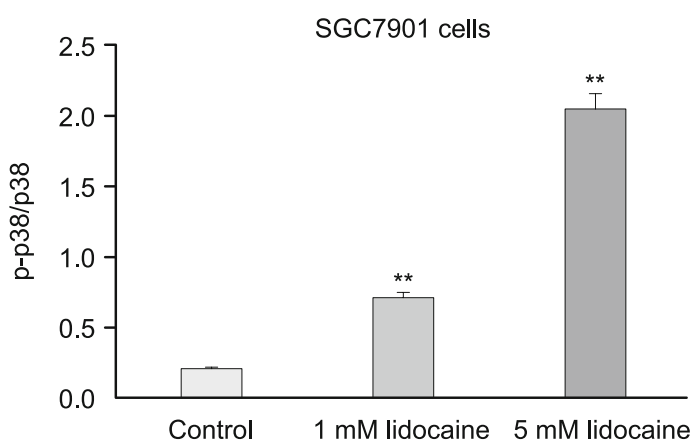

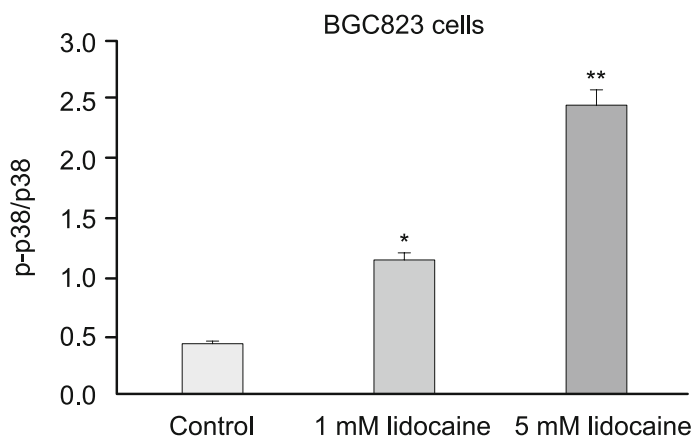

Fig. 4. Lidocaine activated the p38MAPK pathway in gastric cancer cells. (A) SGC7901 cells were treated with various concentrations of lidocaine for $48 \mathrm{~h}$. The protein expression of p-p38 and p38 was detected using western blotting, and the ratio of p-p38/p38 was calculated and presented. (B) BGC823 cells were treated with various concentrations of lidocaine for $48 \mathrm{~h}$. The protein expression of p-p38 and p38 was detected using western blotting, and the ratio of $\mathbf{p}-\mathbf{p} 38 / \mathrm{p} 38$ was calculated and presented. Data are shown as the mean \pm SD. $* *$ p $<0.01$ compared to the control group.

SGC7901 and BGC823 cells, lidocaine dramatically increased phospho-p38 proteins, while had nearly no effect on the expression of $\mathrm{p} 38$ proteins (Fig. 4).

\section{Discussion}

Gastric cancer is a type of gastrointestinal cancer and there is no difference in diagnosis and treatment (32). Although novel methods for treatment of gastric cancer are ample, studies regarding the effects of these treatments have been unsatisfactory (32). According to reports, lidocaine, often used as an anesthetic, inhibits the growth, invasion, and migration of cancer cells. The mechanism of lidocaine in gastric cancer cells has never been identified. Thus, in order to investigate the better therapeutic strategies for gastric cancer, the present study was aimed to investigate the role of lidocaine in gastric cancer.

In our present study, the MTT assay demonstrated that the cell viability of SGC7901 and BGC823 decreased significantly after treatment of various concentrations of lidocaine $(0,0.1,0.5$, 1,5 , and $10 \mathrm{mM}$ ) for $24 \mathrm{~h}, 48 \mathrm{~h}, 72 \mathrm{~h}$. We found that lidocaine inhibited gastric cancer cells proliferation in a dose-dependent and time-dependent manner. However, lidocaine $(0.1 \mathrm{mM})$ had no effects on cell viability. The results from Annexin V-FITC/ PI staining suggested that lidocaine in combination effectively induced SGC7901 and BGC823 cell apoptosis compared to the control cells. Subsequently, to investigate how lidocaine was involved in GC-mediated apoptosis, western blotting assay was used to detect the expression of apoptosis related protein, including Bax and Bcl-2. Our data demonstrated that lidocaine increased Bax level and decreased Bcl-2 level in a dose-dependent manner. These findings indicated that lidocaine could induce cell apoptosis through activating Bax and Bcl-2. Also, incubation of gastric cancer cells with lidocaine inhibited cellular migration and invasion in SGC7901 and BGC823 cells. We also explored the signaling pathways that participated in the effect of lidocaine on gastric cancer cells. At last, we detected that expression of p-p38 and p-p38 was associated with MAPK signal pathway, and it was revealed that lidocaine activated p38MAPK signaling. Our dates indicated that the expression of p-p38 was increased, but the level of p38 was not changed.

In conclusion, the results of the present study provide the first evidence that lidocaine activated MAPK signaling pathways to suppress the proliferation and migration invasion of gastric cancer cells, and to induce gastric cancer cell apoptosis. Moreover, our findings indicated that lidocaine might be a promising anti-cancer drug candidate for gastric cancer treatment. In vivo studies and clinical experiments of this drug should be studied further in future. 


\section{References}

1. Siegel RL, Miller KD, Jemal A. Cancer statistics, 2015. CA Cancer J Clin 2015; 65: 5-29.

2. Torre LA, Bray F, Siegel RL et al. Global cancer statistics, 2012. CA Cancer J Clin 2015; 65: 87-108.

3. Rugge M, Genta RM, Graham DY et al. Chronicles of a cancer foretold: 35 years of gastric cancer risk assessment. Gut 2016; 65: 721-725.

4. Siegel RL, Miller KD, Jemal A. Cancer statistics, 2018. CA Cancer J Clin 2018; 68: 7-30.

5. Chen W, Zheng R, Zhang S et al. The incidences and mortalities of major cancers in China, 2009. Chin J Cancer 2013; 32: 106-112.

6. Comprehensive molecular characterization of gastric adenocarcinoma. Nature 2014; 513: 202-209.

7. Ajani JA, Bentrem DJ, Besh S et al. Gastric cancer, version 2.2013: featured updates to the NCCN Guidelines. J Natl Compr Canc Netw 2013; 11: $531-546$.

8. Saragoni L, Morgagni P, Gardini Aet al. Early gastric cancer: diagnosis, staging, and clinical impact. Evaluation of 530 patients. New elements for an updated definition and classification. Gastric Cancer 2013; 16: 549-554.

9. Carcas LP. Gastric cancer review. J Carcinog 2014; 13: 14.

10. Chou TC. Drug combination studies and their synergy quantification using the Chou-Talalay method. Cancer Res 2010; 70: 440-446.

11. Kanda M, Kodera Y. Molecular mechanisms of peritoneal dissemination in gastric cancer. World J Gastroenterol 2016; 22: 6829-6840.

12. Kodera $Y$. The current state of stomach cancer surgery in the world. Jpn J Clin Oncol 2016.

13. Matuszcak C, Haier J, Hummel R et al. MicroRNAs: promising chemoresistance biomarkers in gastric cancer with diagnostic and therapeutic potential. World J Gastroenterol 2014; 20: 13658-13666.

14. Shi J, Qu YP, Hou P. Pathogenetic mechanisms in gastric cancer. World J Gastroenterol 2014; 20: 13804-13819.

15. Kobrine AI, Evans DE, LeGrys DC et al. Effect of intravenous lidocaine on experimental spinal cord injury. J Neurosurg 1984; 60: 595-601.

16. Cole DJ, Shapiro HM, Drummond JC et al. Halothane, fentanyl/ nitrous oxide, and spinal lidocaine protect against spinal cord injury in the rat. Anesthesiology 1989; 70: 967-972.

17. Zhang X, Han C, He J. Recent Advances in the Diagnosis and Management of Bladder Cancer. Cell Biochem Biophys 2015; 73: 11-15.

18. Kang M, Jeong CW, Kwak C et al. Single, immediate postoperative instillation of chemotherapy in non-muscle invasive bladder cancer: a systematic review and network meta-analysis of randomized clinical trials using different drugs. Oncotarget 2016; 7: 45479-45488.
19. Witjes JA, Hendricksen K. Intravesical pharmacotherapy for nonmuscle-invasive bladder cancer: a critical analysis of currently available drugs, treatment schedules, and long-term results. Eur Urol 2008; 53 : $45-52$.

20. Koga H, Kuroiwa K, Yamaguchi A et al. A randomized controlled trial of short-term versus long-term prophylactic intravesical instillation chemotherapy for recurrence after transurethral resection of Ta/T1 transitional cell carcinoma of the bladder. J Urol 2004; 171: 153-157.

21. Siegel R, Ma J, Zou Z et al. Cancer statistics, 2014. CA Cancer J Clin 2014; 64: 9-29.

22. Chandrasekar T, Erlich A, Zlotta AR. Molecular Characterization of Bladder Cancer. Curr Urol Rep 2018; 19: 107.

23. Logan C, Brown M, Hayne D. Intravesical therapies for bladder cancer - indications and limitations. BJU Int 2012; 110 (Suppl 4): 12-21.

24. Herroeder S, Pecher S, Schonherr ME et al. Systemic lidocaine shortens length of hospital stay after colorectal surgery: a double-blinded, randomized, placebo-controlled trial. Ann Surg 2007; 246: 192-200.

25. Mammoto T, Higashiyama S, Mukai M et al. Infiltration anesthetic lidocaine inhibits cancer cell invasion by modulating ectodomain shedding of heparin-binding epidermal growth factor-like growth factor (HB-EGF). J Cell Physiol 2002; 192: 351-358.

26. Jiang $\mathbf{Y}$, Gou $\mathbf{H}$, Zhu $\mathbf{J}$ et al. Lidocaine inhibits the invasion and migration of TRPV6-expressing cancer cells by TRPV6 downregulation. Oncol Lett 2016; 12: 1164-1170.

27. Piegeler T, Votta-Velis EG, Liu G et al. Antimetastatic potential of amide-linked local anesthetics: inhibition of lung adenocarcinoma cell migration and inflammatory Src signaling independent of sodium channel blockade. Anesthesiology 2012; 117: 548-559.

28. Sakaguchi M, Kuroda Y, Hirose M. The antiproliferative effect of lidocaine on human tongue cancer cells with inhibition of the activity of epidermal growth factor receptor. Anesth Analg 2006; 102: 1103-1107.

29. Chang YC, Hsu YC, Liu CL et al. Local anesthetics induce apoptosis in human thyroid cancer cells through the mitogen-activated protein kinase pathway. PLoS One 2014; 9: e89563.

30. De Oliveira GJ, Fitzgerald P, Streicher LF et al. Systemic lidocaine to improve postoperative quality of recovery after ambulatory laparoscopic surgery. Anesth Analg 2012; 115: 262-267.

31. Tank S, Sputtek A, Kiefmann R. Transfusion-related acute lung injury. Anaesthesist 2013; 62: 254-260.

32. Lee JH, Kim JG, Jung HK et al. Clinical practice guidelines for gastric cancer in Korea: an evidence-based approach. J Gastric Cancer 2014; 14: 87-104. 